06

\title{
О возможности разращивания алмазов в среде углеводородов
}

\author{
() С.К. Брантов, В.Б. Ефимов \\ Институт фризики твердого тела РАН, \\ 142432 Черноголовка, Московская обл., Россия \\ ฯ e-mail: efimov@issp.ac.ru
}

(Поступило в Редакцию 6 сентября 2017 г.)

Исследована возможность увеличения размеров кристаллов алмаза от $25 \mu \mathrm{m}$ путем проведения их отжига при температуре $1450 \mathrm{~K}$ в среде углеводородов. Исходные кристаллы алмаза вводятся в слой поливинилацетата на поверхности монокристалла кремния и подвергаются термической обработке в среде метана низкого давления при наличии внешнего электрического поля напряженностью до $0.04 \mathrm{~V} / \mu \mathrm{m}$. В этих условиях электрически заряженные ионы продуктов диссоциации метана ускоряются и приобретают кинетическую энергию, сопоставимую с достаточной для создания $s p 3$-гибридных связей, что может приводить к увеличению размеров исходных затравочных кристаллитов. Полученные пластины композита характерной толщиной до $1.2 \mathrm{~mm}$, содержащие консолидированные кристаллы алмаза в матрице углерода, могут использоваться в качестве теплопроводящих и электроизолирующих прокладок в устройствах охлаждения изделий электронной техники.

DOI: $10.21883 /$ JTF.2018.06.46015.2472

\section{Введение}

Способы получения алмазоподобных пленок на подложках из кремния и некоторых металлов хорошо изучены. К настоящему времени для их приготовления используются в основном термическое разложение метана в электрическом поле методами „горячей нити“ [1], физическое осаждение из пара в микроволновой плазме [2-4] и развиваемый нами способ пиролиза метана в зазоре между двумя углеродными пластинами, между которыми создается разность электрических потенциалов [5-7].

Параллельно проводятся попытки увеличения алмазов путем пиролиза метана на исходных затравочных кристаллах. Следует отметить работу [8], в которой сообщается о получении крупных друз, из которых удалось выделить желтый алмаз весом 2.3 ct. По ходу процесса растущий на затравке сросток алмаза периодически извлекался из реакционной камеры с удалением слоя пиролитического углерода путем отжига в среде водорода. К сожалению, работа [8] пока не получила продолжения и подтверждения.

В настоящей работе затравочные кристаллы алмаза перед проведением пиролиза метана в электрическом поле жестко крепятся на поверхности полированной пластины кремния слоем поливинилацетата (PVAC), который после карбонизации при нагреве становится дополнительным источником углерода для растущих углеродных кристаллов [9]. В цели работы входят изучение возможности повышения размеров и массы исходных алмазов при пиролизе и консолидации их в друзы. Получаемый композиционный материал, содержащий увеличенные кристаллы алмаза в матрице пирографита, может быть использован для изготовления теплопроводящих прокладок между активными элементами изделий электроники (ИЭ) и радиаторами их охлаждения.

\section{Эксперимент}

В качестве затравочных использовались технические алмазы АСМ 28/20 средними размерами $25 \mu \mathrm{m}$ $\left(\sim 5 \cdot 10^{-6} \mathrm{ct}\right)$. На поверхность полированной пластины толщиной $650 \mu \mathrm{m}$, вырезанной из монокристаллического кремния (ориентация (001)), наносили слой PVAC $\left[-\mathrm{CH}_{2}-\mathrm{CH}\left(\mathrm{OCOCH}_{3}\right)-\right]_{n}$, в который втирали алмазный порошок. Далее пластину помещали в реакционную ячейку, показанную схематически на рис. 1. Расстояние между верхней и нижней пластинами составляло $\sim 2 \mathrm{~mm}$. Как и в работе [6], для нагрева нижней пластины через нее пропускают электрический ток $I_{1} \sim 700 \mathrm{~A}$, а между верхней и нижней пластинами прикладывают постоянную разность потенциалов $\Delta U$. После откачки рабочей камеры до давления $\sim 7$ Ра подложку прогревали до температуры $1400-1450 \mathrm{~K}$ и в камеру вводили газообразный метан до начального давления $600 \mathrm{~Pa}$. Потенциал смещения между пластинами поддерживали на уровне $\Delta U \approx 80 \mathrm{~V}$. При этом между пластинами

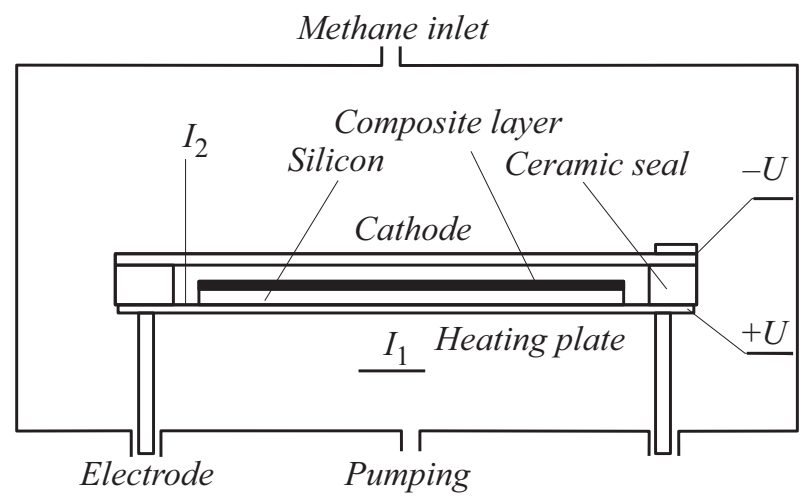

Рис. 1. Принципиальная схема реакционной ячейки для проведения разращивания алмазов. 
возникал ток $I_{2}$, плотность которого не превышала $120 \mu \mathrm{A} / \mathrm{cm}^{2}$. По мере увеличения общего давления в результате выделения водорода давление газа в камере возрастало, поэтому мы периодически откачивали газ и напускали свежий метан. При нагреве в среде метана слой PVAC превращается в слой пиролитического углерода и приобретает характерный для последнего металлический блеск.

Хорошо известно [9], что в описанных условиях выделяющийся при распаде метана атомарный водород активно газифицирует графит и практически не взаимодействует с алмазом, что создает условия для его преимущественного роста. Время выдержки образца при повышенной температуре составляет 3-4h. По завершении процесса слой PVAC отделяется от подложки кремния механически, либо растворением кремния в кислотах. После измельчения слоя в агатовой ступке из него выделяются образцы для дальнейших исследований.

Для изучения транспортных характеристик полученного композита использовались плоские образцы характерными размерами $\sim 15 \times 40 \mathrm{~mm}$ и толщиной 0.5-1.2 mm. Измерения электропроводности проводились четырехзондовым методом на постоянном токе при комнатной температуре. Токовые и потенциальные медные контакты крепились к образцу серебряной пастой. Расстояние между потенциальными контактами составляло $3.1 \mathrm{~cm}$. Сечение образца $\sim 0.2 \mathrm{~cm}^{2}$. Удельное сопротивление композита составило $\sim 2000 \Omega \cdot \mu \mathrm{m}$. Для измерений теплопроводности полученного композита была использована методика стационарного теплового потока.

\section{Основные характеристики полученного материала}

О структуре и физических свойствах полученного материала судили по результатам измерений методами оптической, электронной микроскопии и дифракции рентгеновских лучей, а также измерений электрического сопротивления и теплопроводности образцов.

На рис. 2 приведена оптическая микрофотография исходной алмазной крошки АСМ 28/20 детонационного синтеза, которую использовали в качестве затравок. Рентгеновские исследования показали наличие в таких крошках наноразмерных кристаллитов. Следует отметить множество дефектов на внешней поверхности отдельных кристаллитов, что означает, что они обладают высокой поверхностной энергией.

Рис. 3, a иллюстрирует, как выглядит поверхность слоя PVAC с затравочными кристаллами по завершении процесса обработки в метане. Наблюдается существенное увеличение размеров отдельных кристаллитов и сращивание их в друзы. Можно видеть, что исходные затравочные кристаллы увеличиваются в размерах почти вдвое и углеродные кристаллы достигают размеров до

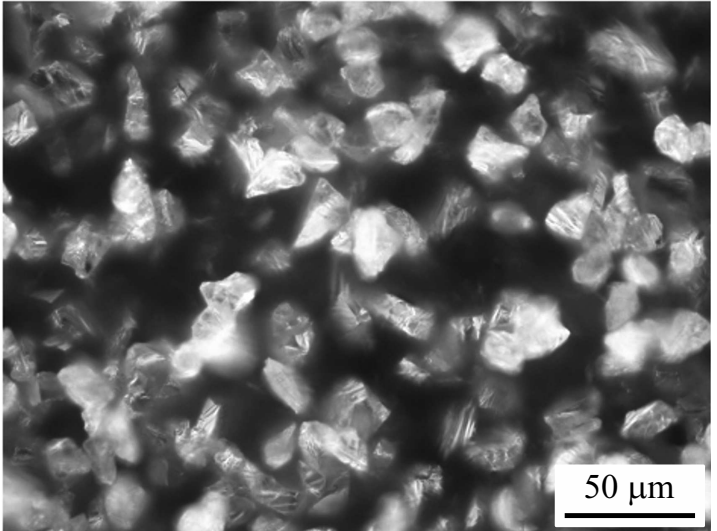

Рис. 2. Оптическая микрофотография исходных кристаллов алмаза АCM 28/20.

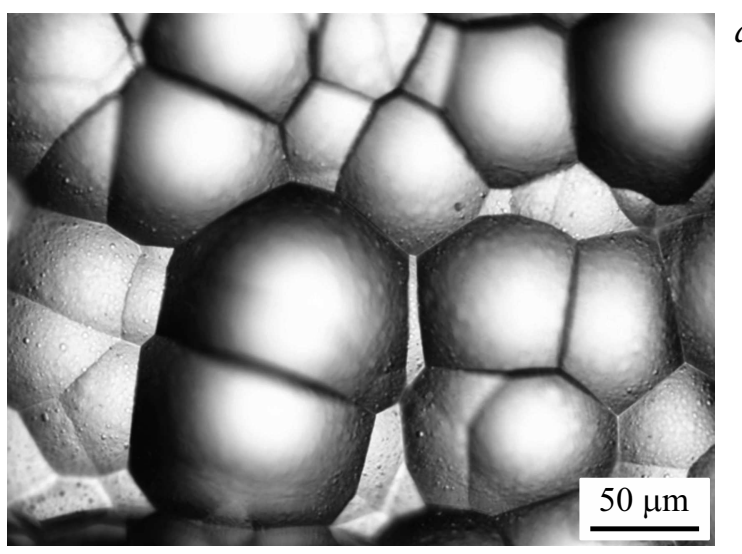

Composite diamond layer

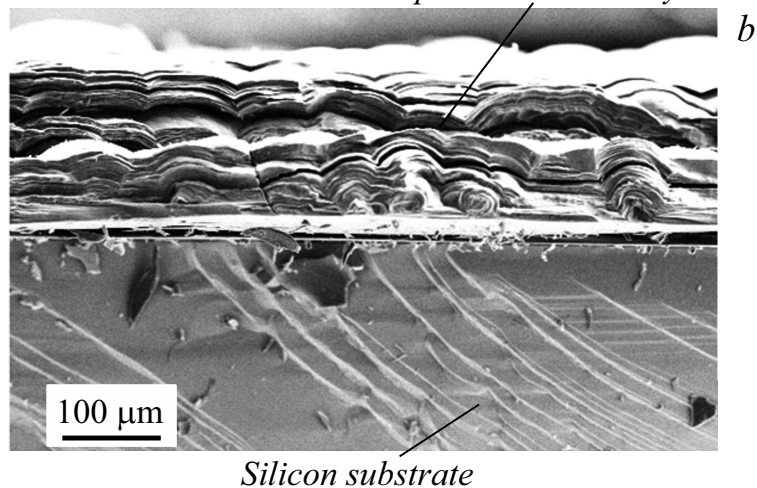

Pис. 3. $a-$ оптическая микрофотография поверхности слоя PVAC с алмазами по завершении процесса разращивания. $b-$ SEM-изображение поперечного сечения слоя PVAC с алмазами на поверхности подложки кремния.

$50 \mu \mathrm{m}$. Геометрические размеры выделенных из композита углеродных друз с вкрапленными алмазными зернами (рис. 4) достигают $2 \mathrm{~mm}$. Как показали наши измерения, при длительном отжиге в метановой атмосфере на поверхности исходных алмазных кристаллов наращивается слой пиролитического углерода, и процесс формирования алмазной фазы на этом прекращается [10-12]. 


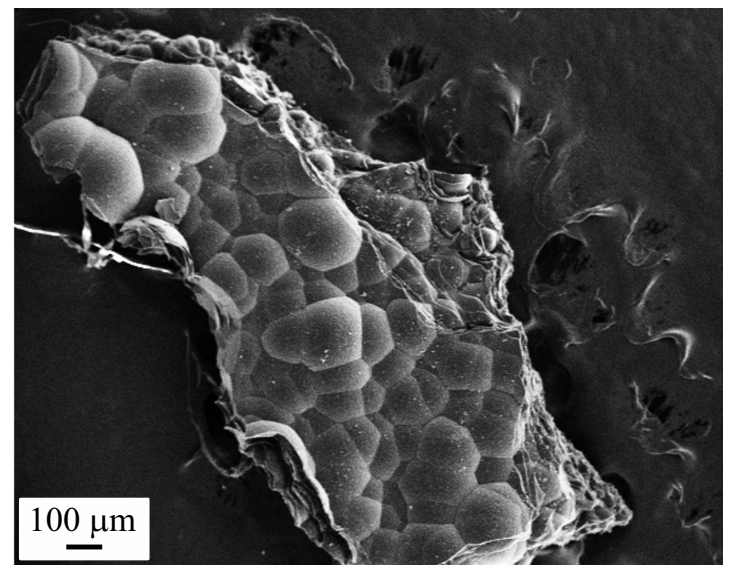

Рис. 4. Вид алмазной друзы после отделения от подложки кремния.

На рис. $3, b$ приведено изображение поверхности излома образца композита.

Для более детального изучения структуры полученных кристаллов слой композита отделялся от подложки кремния и подвергался механическому измельчению в агатовой ступке. После просеивания через сито с ячейкой $400 \mu \mathrm{m}$ кристаллы, которые не прошли сквозь ячейки сита, были изучены методом сканирующей электронной микроскопии (SEM). Результаты этих исследований приведены на рис. 4.

На рис. 5 приведен XRD-спектр, снятый с поверхности пластины композита. Помимо линий алмаза (111) и кристаллического графита (220), присутствовавших на спектре исходного порошка алмазов, обнаружен уширенный пик слоистого графита (002). Аморфный углерод не наблюдается. Сравнение рентгеновских спектров затравочных алмазных кристаллитов и композита после наращивания показывает сужение пиков, соответствующих структуре алмаза для композита, что свидетельствует о резком увеличении размеров алмазных кристаллитов в полученном материале.

Для оценки теплопроводности полученного композита при комнатных температурах была использована методика стационарного теплового потока. На свободном торце образца крепился нагреватель, противоположный торец образца крепили в медной обойме, которую использовали для отвода тепла, выделяемого на нагревателе. Возникающая разность температур измерялась медьконстантановой термопарой (диаметр проводов $50 \mu \mathrm{m}$ ), которая предварительно калибровалась. Расстояние между контактами термопары составляло порядка $20 \mathrm{~mm}$ в разных экспериментах. Для предотвращения утечек тепла от нагревателя в окружающее пространство образец для измерения теплопроводности был помещен в пенопластовый футляр. Измерения проводились с небольшими нагревами образца при увеличении величины нагрева и при его уменьшении. Результаты измерений приведены на рис. 6. Измерения теплопро- водности показали, что коэффициент теплопроводности образцов материала, прошедших стадию рекристаллизации, составляет $k \approx 92.8 \mathrm{~W} /(\mathrm{m} \cdot \mathrm{K})$, тогда как тот же параметр для исходного материала в виде слоя РVAC с алмазным наполнителем $k \approx 13.8 \mathrm{~W} /(\mathrm{m} \cdot \mathrm{K})$. Теплопроводность электронной системы $k_{e}$, оцениваемая из соотношения Видемана-Франца, приводит к значению $k_{e} \approx 3.5 \cdot 10^{-2} \mathrm{~W} /(\mathrm{m} \cdot \mathrm{K})$, следовательно, вклад переноса тепла носителями заряда пренебрежимо мал и основную роль играет решеточная компонента - перенос тепла фононами. Отметим, что удельная теплопроводность исследованных нами образцов оказалась приблизительно на порядок ниже теплопроводности алмазного монокристалла [13]. Теплопроводность совершенных алмаз-

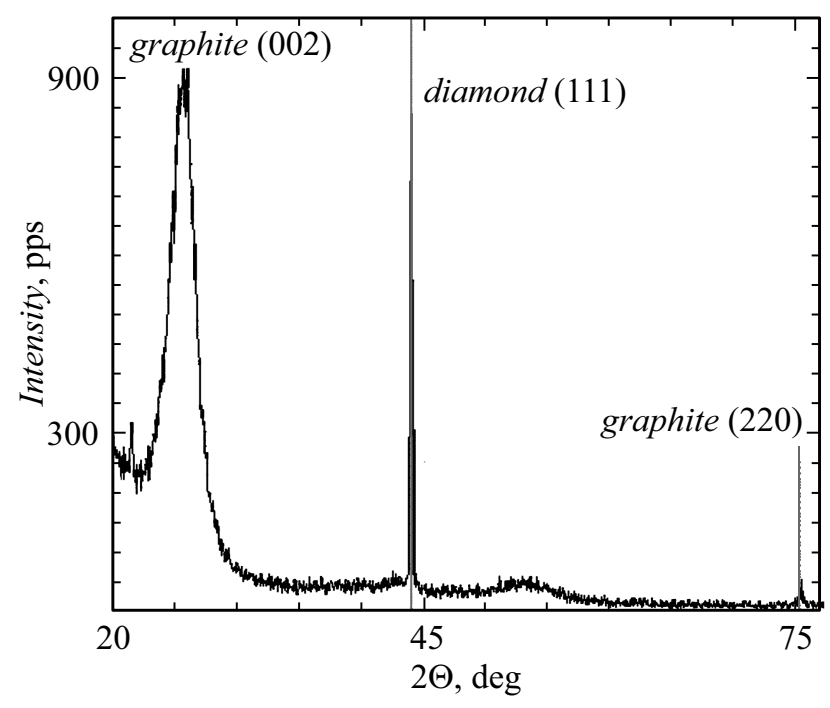

Pис. 5. XRD спектр полученного композита.

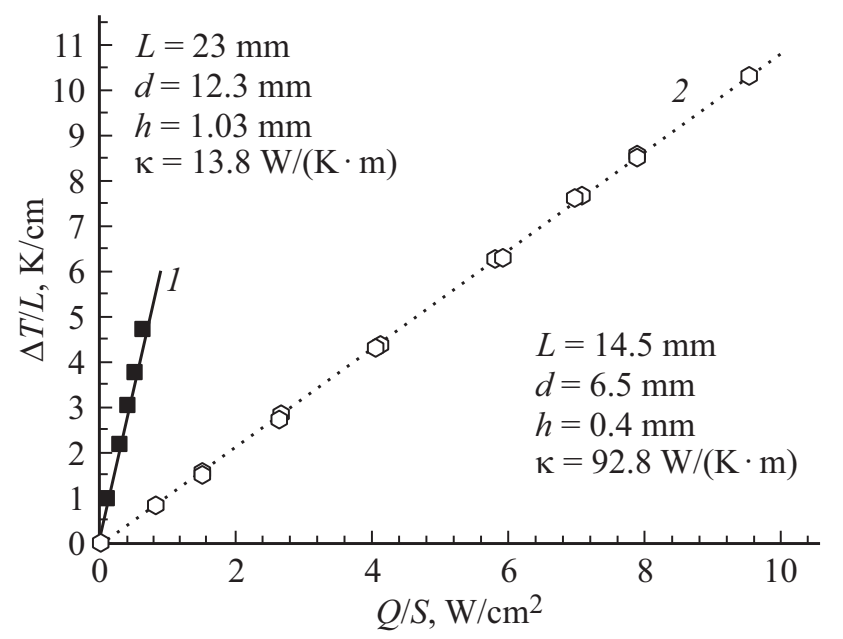

Рис. 6. Результаты оценки теплопроводности полученного материала методом стационарного теплового потока. 1 исходный материал в виде слоя PVAC с наполнителем из алмазного порошка на поверхности слюды, 2 - материал, прошедший стадию разращивания исходных алмазов в электрическом поле. 
ных кристаллов при комнатных температурах ограничивается фонон-фононным рассеянием, поэтому их теплопроводность быстро возрастает при понижении температуры. Предыдущие измерения теплопроводности алмазных пленок, размеры кристаллитов в которых были порядка $100 \mathrm{~nm}$ и $1 \mu \mathrm{m}$ [13-15], показали, что при комнатной температуре теплопроводность поликристаллических образцов ограничивается рассеянием фононов на границах кристаллитов и может быть в несколько раз ниже теплопроводности совершенных монокристаллов. Относительно низкая теплопроводность измеренных в настоящей работе образцов может быть связана с сильным рассеянием фононов на межкристаллических границах и на примесях в алмазных кристаллитах.

Как было сказано выше, размеры кристаллитов в исследуемом композите (рис. 3) достигают $50 \mu \mathrm{m}$, что существенно ниже характерной длины свободного пробега фононов при фонон-фононном рассеянии в алмазе при комнатной температуре. Стоит отметить, что измеренная теплопроводность может быть связана с переносом тепла по поликристаллическому графиту, существование которого в композите показывают как рентгеновские спектры, так и исследования сканирующей микроскопии.

\section{Обсуждение результатов}

При проведении описанного выше процесса рекристаллизации исходные кристаллы алмаза подвергаются следующим воздействиям: (i) нагрев в среде метана; (ii) присутствие матрицы PVAC, содержащей углерод; (iii) протекание пиролиза как метана, так и матрицы PVAC при значительной напряженности внешнего электрического поля. Достаточно сложно учесть взаимный вклад перечисленных факторов этих воздействий. В результате проведения процесса на поверхности пластины кремния формируется слой композиционного материала, состоящий из алмазных кристаллитов и углеродной матрицы, который может быть отделен от подложки кремния.

Для практического использования материалов данного типа с целью охлаждения изделий электроники требуется сочетание относительно высокой теплопроводности с низкой электропроводностью, чего невозможно достичь при применении металлов и их сплавов. Дополнительно имеет значение пластичность материала прокладки, поскольку поверхность радиатора в области контакта с ИЭ содержит ребра или иглы. Предложенный композиционный материал способен деформироваться без хрупкого разрушения. Полученные нами значения теплопроводности $\sim 90-100 \mathrm{~W} /(\mathrm{m} \cdot \mathrm{K})$ и удельного электросопротивления $\sim 2000 \Omega \cdot \mu$ m при комнатных температурах не являются выдающимися в указанном контексте, но позволяют рассчитывать на возможность практического использования полученного композита. Алмазоподобные пленки [14] имеют лучшие характеристики, но их сложно использовать после отделения от подложки кремния. Для сравнения ниже приведены данные по теплопроводности некоторых материалов, которые могут быть использованы для изготовления теплопроводящих прокладок [16]: гибкая углеродная фольга $-4.8 \mathrm{~W} /(\mathrm{m} \cdot \mathrm{K})$; стеклоуглерод $-3-8 \mathrm{~W} /(\mathrm{m} \cdot \mathrm{K})$; сапфир - $37 \mathrm{~W} /(\mathrm{m} \cdot \mathrm{K})$. Теплопроводящие пасты $2-6 \mathrm{~W} /(\mathrm{m} \cdot \mathrm{K})$, при этом их теплопроводность заметно снижается при высыхании. Оптимальным материалом является окись бериллия $\mathrm{BeO}$, теплопроводность которой составляет $209 \mathrm{~W} /(\mathrm{m} \cdot \mathrm{K})$, но ее использование в устройствах гражданского назначения запрещено из-за высокой токсичности.

\section{Заключение}

Предложен способ получения композиционного материала, содержащего наполнитель в форме кристаллов алмаза в матрице пиролитического углерода. В процессе термической обработки в среде метана низкого давления в присутствии внешнего электрического поля исходные кристаллы алмаза увеличиваются в размерах, улучшается их кристаллическая структура, а сами кристаллиты сращиваются в углеродные друзы. После сращивания друз между собой дальнейшего увеличение массы композита не наблюдается. Выделенные из композита кристаллы алмаза технической ценности не представляют, но слои композита, состоящие из алмазных кристаллитов и пиролитического графита, могут быть использованы в технологии микроэлектроники для изготовления элементов систем охлаждения микросхем и отдельных активных компонентов.

Авторы благодарны А.С. Аронину за проведение электронно-микроскопических исследований, В.И. Орлову за выполнение оптических микрофотографий, И.М. Шмытько за получение спектров дифракции рентгеновских лучей и Л.П. Межову-Деглину за полезные обсуждения.

\section{Список литературы}

[1] Gray K.J., Windishmann H. // Diamond Relat. Mater. 1999. Vol. 8. P. 903-908.

[2] May P.W. // Phil. Trans. Roy. Soc. Lond. A. 2000. Vol. 358. P. 473-495.

[3] Liang Q., Yan C.S., Meng J., Lai J., Krasnicki S., Mao H.K., Hemley R.J. // Diamond Relat. Mater. 2009. Vol. 18. P. 698-705.

[4] Teng K., Chen H., Tzeng G., Tang C., Cheng H., Lin J. // J. Appl. Phys. 2012. Vol. 111. P. 053701. doi:10.1063/1. 3687918

[5] Брантов С.К., Божкко С.И., Рыжккин И.А., Шмытько И., Орлов В.И. // Письма в ЖТФ. 2013. Т. 39. Вып. 2. С. 21-28.

[6] Брантов С.К., Терещенко А.Н., Штейнман Э.А., Якимов Е.Б. // ЖТФ. 2016. Т. 86. Вып. 3. С. 110-114.

[7] Брантов С.К., Борисенко Д.Н. // Патент РФ № 2585634 C1. 2016. бюлл. 15. 
[8] Meng Y.F., Yan C.S., Krasnicki S., Liang Q., Lai J., Shu H., Yu T., Steele A., Mao H.K., Hemley R.J. // Phys. Status Solidi A. 2012. Vol. 209. N 1. P. 101-104.

[9] May P.W. // Endeavour Magazine. 1995. Vol. 19. N 3. P. $101-106$

[10] Kobashi K., Nishimura K., Kawate Y., Horiuchi T. // Phys. Rev. B. 1988. Vol. 38. N 6. P. 11-14.

[11] Kamo M., Sato Y., Matsumoto S., Setaka N. // J. Crystal Growth. 1983. Vol. 62. P. 642-644.

[12] Matsumoto S., Sato Y., Kamo M., Setaka N. // J. Appl. Phys. 1982. Vol. 21. P. 347-352.

[13] Lanhua Wei, Kuo P.K., Thomas R.L., Anthony T.R., Banholzer W.F. // Phys. Rev. Lett. 1993. Vol. 70. P. 3764-3768.

[14] Efimov V.B., Mezhov-Deglin L.P. // Physica B: Cond. Matter. 1999. P. 263-264.

[15] Efimov V., Mezhov-Deglin L. // Phys. Stat. Sol. C. 2004. Vol. 1. P. $2987-2990$.

[16] Брантов С.К. // Функциональные композиты на основе углерода. 2013. М.: Нобель Пресс, 142 с. ISBN: 978-5-578-55424-5. 